\title{
Thermodynamic structure of the Atmospheric Boundary Layer over the Arabian Sea and the Indian Ocean during pre-INDOEX and INDOEX-FFP campaigns
}

\author{
M. V. Ramana, Praveena Krishnan, S. Muraleedharan Nair, and P. K. Kunhikrishnan \\ Space Physics Laboratory, Vikram Sarabhai Space Centre, Thiruvananthapuram - 695 022, India \\ Received: 21 July 2003 - Revised: 27 February 2004 - Accepted: 30 March 2004 - Published: 7 September 2004
}

\begin{abstract}
Spatial and temporal variability of the Marine Atmospheric Boundary Layer (MABL) height for the Indian Ocean Experiment (INDOEX) study period are examined using the data collected through Cross-chained LORAN (LongRange Aid to Navigation) Atmospheric Sounding System (CLASS) launchings during the Northern Hemispheric winter monsoon period. This paper reports the results of the analyses of the data collected during the pre-INDOEX (1997) and the INDOEX-First Field Phase (FFP; 1998) in the latitude range $14^{\circ} \mathrm{N}$ to $20^{\circ} \mathrm{S}$ over the Arabian Sea and the Indian Ocean. Mixed layer heights are derived from thermodynamic profiles and they indicated the variability of heights ranging from $400 \mathrm{~m}$ to $1100 \mathrm{~m}$ during daytime depending upon the location. Mixed layer heights over the Indian Ocean are slightly higher during the INDOEX-FFP than the preINDOEX due to anomalous conditions prevailing during the INDOEX-FFP. The trade wind inversion height varied from $2.3 \mathrm{~km}$ to $4.5 \mathrm{~km}$ during the pre-INDOEX and from $0.4 \mathrm{~km}$ to $2.5 \mathrm{~km}$ during the INDOEX-FFP. Elevated plumes of polluted air (lofted aerosol plumes) above the marine boundary layer are observed from thermodynamic profiles of the lower troposphere during the INDOEX-FFP. These elevated plumes are examined using 5-day back trajectory analysis and show that one group of air mass travelled a long way from Saudi Arabia and Iran/Iraq through India before reaching the location of measurement, while the other air mass originates from India and the Bay of Bengal.
\end{abstract}

Key words. Meteorology and atmospheric dynamics (tropical meteorology, general circulation, ocean-atmosphere interaction, convective processes) - Atmospheric composition and structure (aerosols and particles, pollution-urban arid regional) - Oceanography physical (air-sea interactions)

Correspondence to: P. K. Kunhikrishnan

(pk_kunhikrishnan@vssc.org)

\section{Introduction}

INDian Ocean EXperiment (INDOEX) is an international field campaign research programme aimed at understanding the interaction between aerosols and radiation, the transport and dispersion of trace species and pollutants of continental origin over the Indian Ocean during the north-east Asian winter monsoon period (Ramanathan et al., 1995; Mitra, 1999). In order to understand the above mechanisms, additional information, like atmospheric boundary layer depth and the height of the monsoonal inversion, with particular emphasis on diurnal variability and variation from the Indian coast up to the Inter Tropical Convergence Zone (ITCZ) are required. For air pollution studies the mixing height is an important parameter because it defines the height to which pollutants released near the ground are vertically mixed by (dry-) convective or mechanical turbulence, typically within one hour or less (Beyrich et al., 1996). In the frame of the INDOEX, extensive dynamical and thermodynamical measurements were made over the Arabian Sea and Indian Ocean during the winter (dry) season (Ramana et al., 2004).

In an effort to understand the structure and characteristics of the Marine Atmospheric Boundary Layer (MABL) over the equatorial pacific region and Atlantic Ocean, extensive field experiments were conducted which include: Barbados Oceanographic Meteorological Experiment (BOMEX) (Holland and Rasmusson, 1973; Dunckel et al., 1974), Atlantic Tradewind Experiment (ATEX) (Augstein et al., 1973, 1974), Global Atmospheric research program Atlantic Tropical Experiment (GATE) (Augstein, 1978; Houze and Betts, 1981), Air Mass Transformation Experiment (AMTEX) (Mitsuta, 1977-1979; Kondo, 1975), Joint Air-Sea Interaction (JASIN) (Nicholls, 1985; Shaw and Businger, 1985), Heat Exchange over Sea (HEXOS) (Katsaros et al., 1987; Smith et al., 1992), Tropical Ocean Global Atmosphere (TOGA) (Young et al., 1992; Halpern, 1996), TOGA and Coupled Ocean Atmospheric Response Experiment (TOGA-COARE) (Webster and Lukus, 1992; Fairall et al., 1996). MABL studies during the Northern Hemisphere 


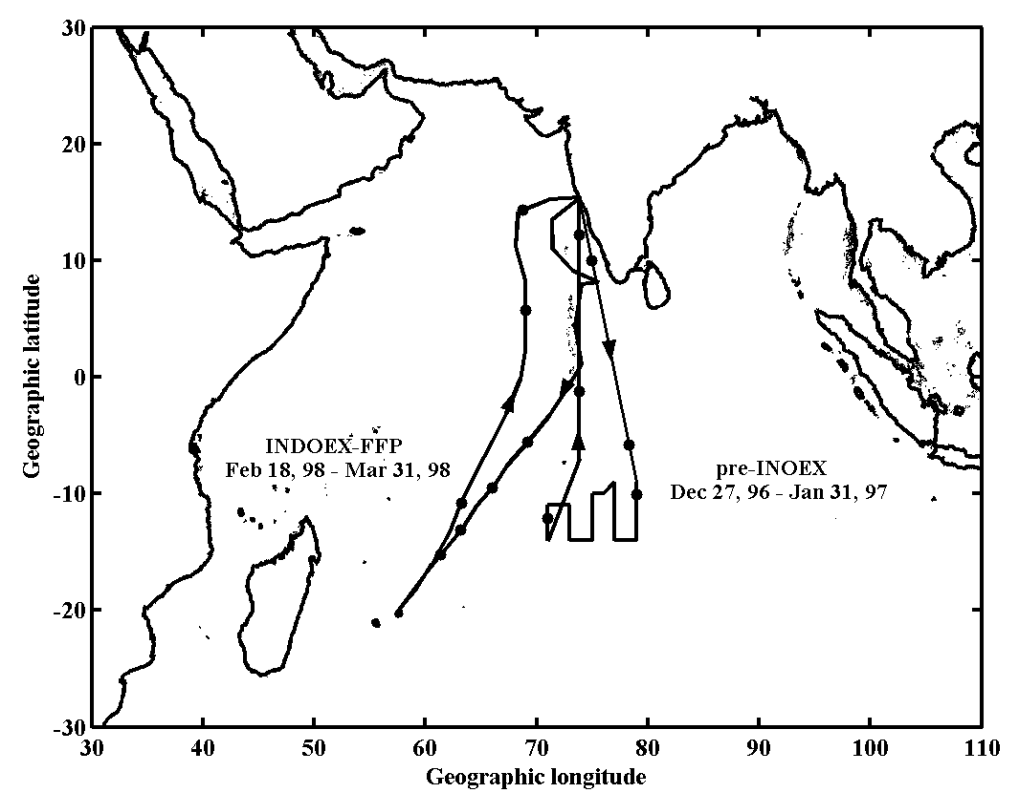

Fig. 1. Map showing the cruise tracks of the pre-INDOEX and INDOEX-FFP. Filled circles along the cruise tracks represent the soundings, which are used in Figs. 2, 3, 6 and 7.

winter season over the Arabian Sea and the Indian are not many. It is in this context that the data collected during the INDOEX attains prime scientific significance.

During the Northern Hemispheric winter the meridional circulation over the Arabian Sea and the Indian Ocean is often idealized as an equatorward flow capped by the trade wind inversion that weakens and increases in height equatorward. Inter Tropical Convergence Zone (ITCZ) is known to be associated with deep convection, where subsidence gives way to mean upward motion, called the "disturbed condition". In contrast, during the "undisturbed conditions" clouds are generally trapped beneath the subsidence inversion generated by the subtropical highs. Consequently, the tropical Indian Ocean is a region of transition between the undisturbed trade wind subsidence and the disturbed convective region of the ITCZ. This is only an average picture, however, because this region is basically void of data; the transition between undisturbed and disturbed conditions has not yet been as well documented over the Indian Ocean as it has been in the Atlantic and the Pacific Oceans.

A series of INDOEX cruises in 1996, 1997, and 1998 were conducted during winter months of December to March before the main phase in 1999 (Mitra, 1999). In this paper, data collected during the pre-INDOEX (winter 1997) and the INDOEX-First Field Phase (FFP; winter 1998) are investigated. The primary focus of this study is to investigate the thermodynamic structure of the MABL under horizontal variability of the Sea Surface Temperature (SST) and air masses due to meridional advection during the pre-INDOEX and the INDOEX-FFP through ship-borne in-situ measurements.

\section{Data}

The present study is based on tropospheric soundings made from the ship platform of ORV-SagarKanya during the preINDOEX (27 December 1996-31 January 1997) in the latitude range $15^{\circ} \mathrm{N}$ to $14^{\circ} \mathrm{S}$ and the INDOEX-FFP (18 February $1998-31$ March 1998) in the latitude range $15^{\circ} \mathrm{N}$ to $20^{\circ} \mathrm{S}$. Figure 1 shows the map of pre-INDOEX and INDOEX-FFP cruise tracks. During the pre-INDOEX cruise the Cross-chained LORAN (Long-Range Aid to Navigation) Atmospheric Sounding System (CLASS) along with Global Positioning Systems (GPS) made available by National Centre for Atmospheric Research (NCAR) were used for profiling pressure $(P)$, temperature $(T)$, relative humidity $(R H)$, dew-point temperature $\left(T_{d}\right)$, wind speed $(W S)$ and wind direction $(W D)$ from the ship along the entire cruise track. Launchings were made every day at 06:00 and 14:00 IST (all timings are in Indian Standard Time, IST $=\mathrm{UTC}+5.30 \mathrm{~h}$ ). A total of 46 ascents were successfully undertaken during the pre-INDOEX with vertical height resolution of 30 to $40 \mathrm{~m}$, up to a height of 17 to $20 \mathrm{~km}$. Similarly, during the INDOEXFFP cruise, the CLASS was used for profiling without GPS, hence, only $T, R H, T_{d}$, and $P$ could be measured. A total of 47 sonde ascents were executed during the INDOEXFFP from $4.5^{\circ} \mathrm{N}$ onwards at 06:00 and 14:00 IST every day and they too attained 17 to $20 \mathrm{~km}$ altitudes. The uncertainties in the temperature and pressure measurements are $0.5^{\circ} \mathrm{C}$ and $1.0 \mathrm{mb}$, respectively. The uncertainties of the humidity measurements are $1 \%$ near the surface and $10-15 \%$ between $7-15 \mathrm{~km}$ altitudes.

Potential temperature $(\theta)$, virtual potential temperature $\left(\theta_{v}\right)$, mixing ratio $(q)$, saturated mixing ratio $\left(q_{s}\right)$, equivalent potential temperature $\left(\theta_{e}\right)$ and saturated equivalent potential 


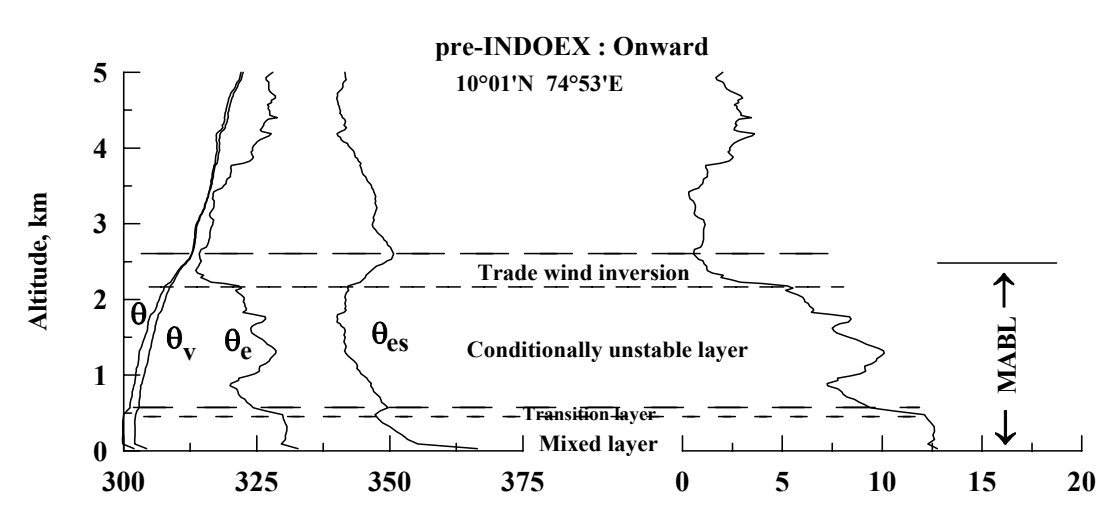

(a)

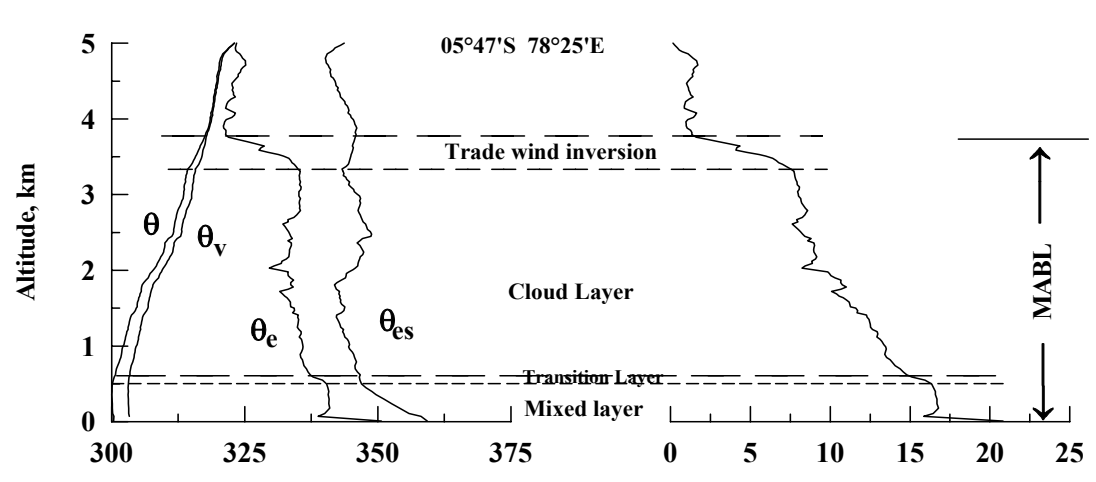

(b)

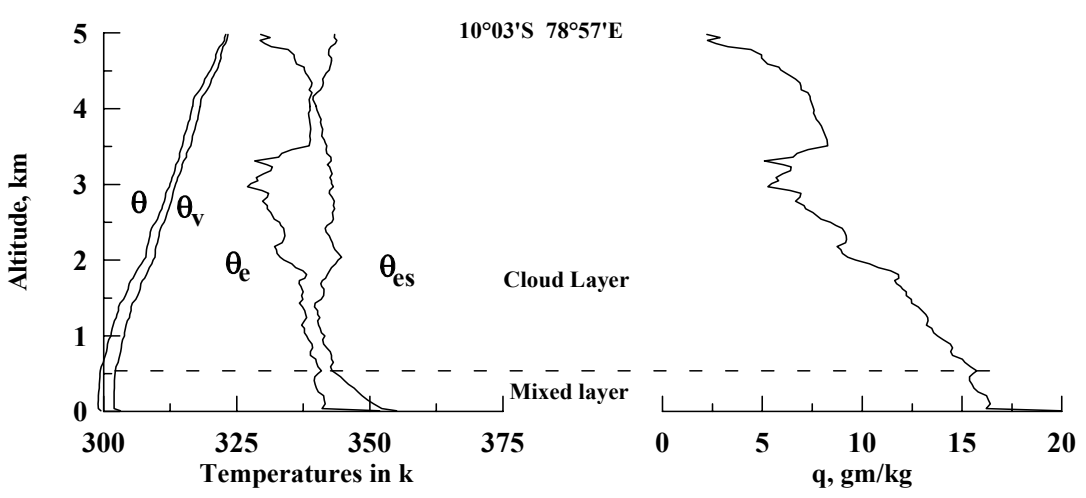

(c)

Fig. 2. Altitude profiles of potential temperature $(\theta)$, virtual potential temperature $\left(\theta_{v}\right)$, equivalent potential temperature $\left(\theta_{e}\right)$, saturated equivalent potential temperature $\left(\theta_{e s}\right)$ and mixing ratio $(q)$ during the on ward track of pre-INDOEX.

temperature $\left(\theta_{e s}\right)$ are calculated from $T, T_{d}$ and $R H . \theta_{e}$ is conserved for both dry and moist adiabatic processes in the absence of precipitation (Betts, 1973), and therefore is an excellent tracer of the air motion. Different layers and the presence of stable layers are identified and their heights are measured from the profiles within the boundary layer, based on the relative invariance of $\theta, \theta_{v}, \theta_{e}, \theta_{e s}$ and $q$. In the subsequent sections, the observed features of the MABL during the pre-INDOEX and the INDOEX-FFP are given.

\section{Thermodynamic structure}

The present study is an attempt towards attaining a better understanding of the vertical structure of the MABL over the tropical Indian Ocean and the Arabian Sea. We confined our analysis of all the profiles from the surface to an altitude of $5 \mathrm{~km}$. We also paid attention to the inversion layers (stable layers) because of their crucial role in controlling the vertical and horizontal transport of aerosols and trace gases in the lower atmosphere.

\subsection{Pre-INDOEX}

The vertical profiles of $\theta, \theta_{v}, \theta_{e}, \theta_{e s}$ and $q$ at $10^{\circ} 01^{\prime} \mathrm{N}$ $74^{\circ} 53^{\prime} \mathrm{E}$ over the Arabian Sea during 14:00 IST up to $5 \mathrm{~km}$ altitude are shown in Fig. $2 \mathrm{a}$. The profiles of $\theta, \theta_{v}, \theta_{e}$ and $q$ above the ocean surface show a shallow layer through which the vertical gradients are nearly zero up to $500 \mathrm{~m}$ and are following a dry adiabatic lapse rate. These are the 

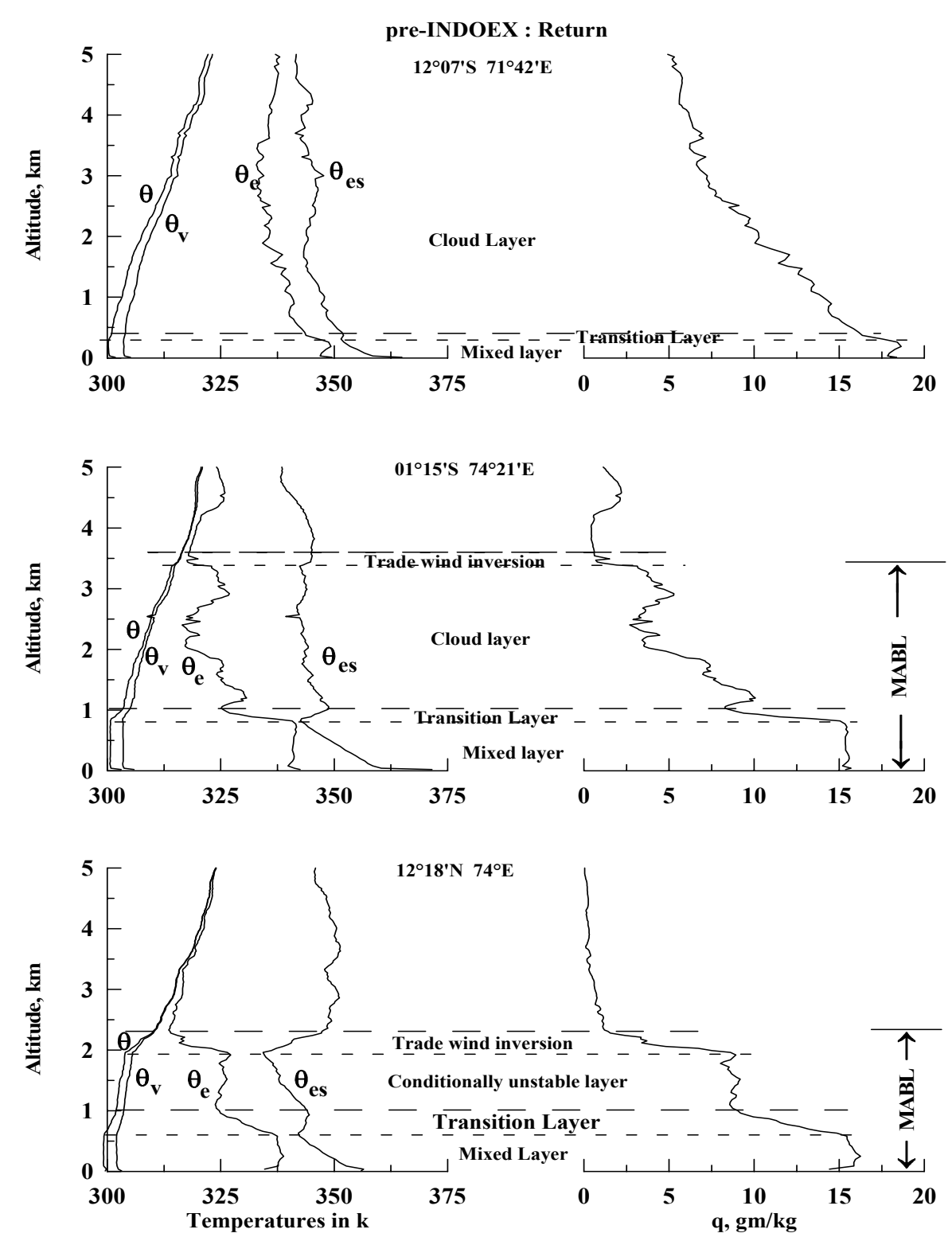

Fig. 3. Altitude profiles of potential temperature $(\theta)$, virtual potential temperature $\left(\theta_{v}\right)$, equivalent potential temperature $\left(\theta_{e}\right)$, saturated equivalent potential temperature $\left(\theta_{e s}\right)$ and mixing ratio $(q)$ during the return track of pre-INDOEX.

characteristics of a mixed layer and we denote this layer as mixed layer. This layer has more moisture than the layers above (evident from $q$ profile). Above the $500 \mathrm{~m}$ altitudes an inversion layer of around $75 \mathrm{~m}$ width is seen in these profiles. The vertical gradients of $\theta$ and $\theta_{v}$ became positive above the inversion layer up to around $2.2 \mathrm{~km}$, with lapse rates lying between the moist and dry adiabatic values, whereas, on average, $\theta_{e}$ is decreasing with height in this region $\left(\partial \theta_{e} / \partial \mathrm{Z}<0\right)$, indicating a convective instability region with respect to saturated parcel displacements. $\theta_{e s}$ is also decreasing with height $\left(\partial \theta_{e s} / \partial \mathbf{Z}<0\right)$ above the transition layer up to $2.2 \mathrm{~km}$ indicating the conditionally unstable atmosphere. We denoted this region as an conditionally unstable layer and whose lower boundary is the inversion level. The inversion layer, which is separating the mixed layer and the conditionally unstable layer, is named as a transition layer. The decrease in $\theta_{e}$ is rapid across the transition layer, which separates the conditionally unstable layer air from the surface mixed layer.

The conditionally unstable layer is capped by an inversion layer, which is called a trade wind inversion layer; where $\theta$, $\theta_{v}, \theta_{e s}$ are increasing and $q$ and $\theta_{e}$ have a greater decrease with height than in the layers below. The trade wind inversion top, which acts as an interface between MABL and the free atmosphere, is marked by a maximum of $\theta_{e s}$ and a corresponding minimum in $\theta_{e}$ (Betts and Albrecht, 1987). In general, $\theta_{e}$ attains a minimum value at the level of separation between moist and dry air. The altitude of the $\theta_{e s}$ minimum and maximum, respectively, corresponds to the base 

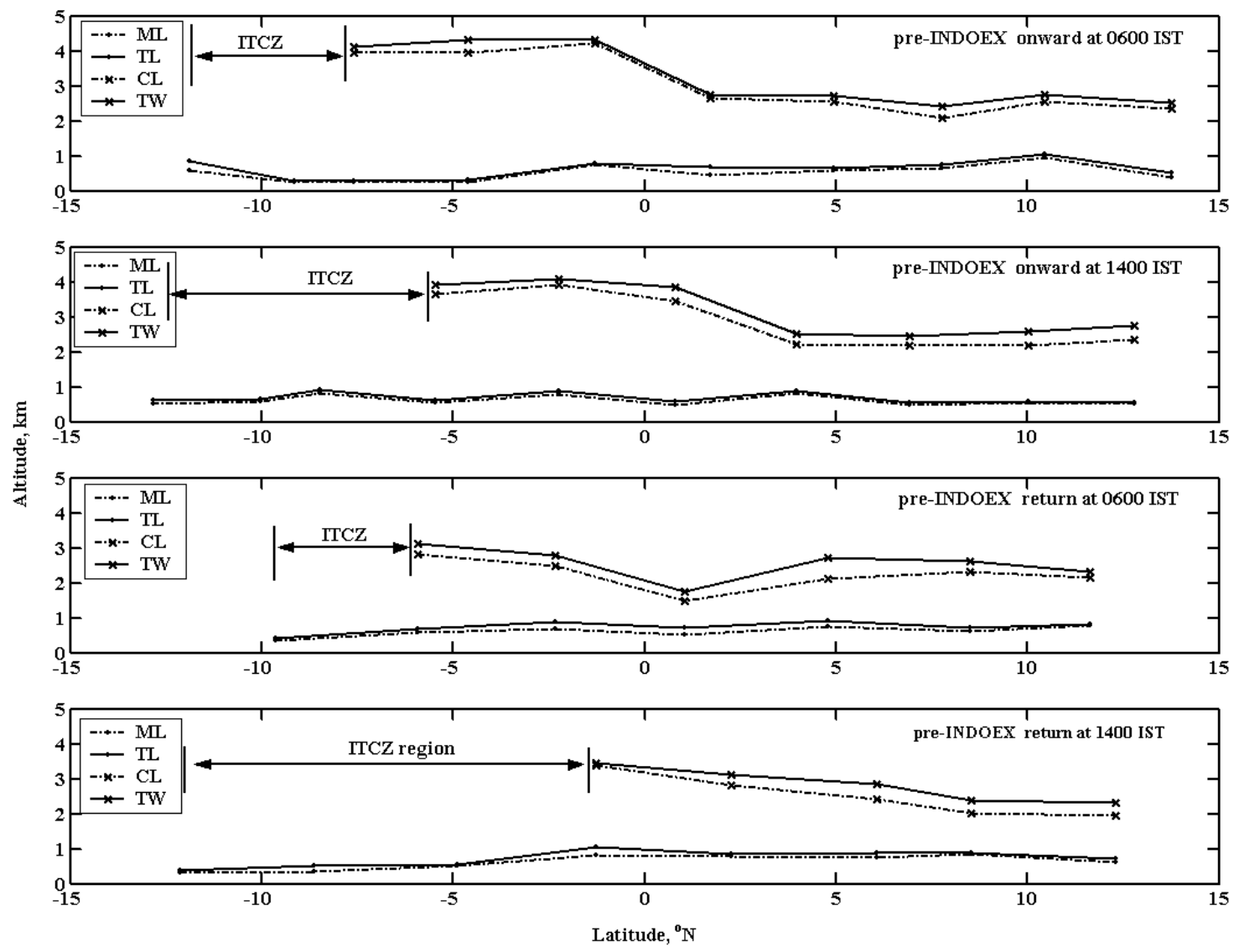

Fig. 4. Latitudinal variation of Mixed Layer (ML) height, Transition Layer (TL) height, Cloud layer (CL) and Trade Wind inversion (TW) heights during pre-INDOEX. The continuous and dotted lines joined with the dot symbol represent the TL height and ML height, respectively. The continuous and dotted lines joined with the cross symbol represent the TW height, and CL height respectively.

and top of the trade wind inversion. The $\theta_{e}$ attains a minimum and $\theta_{e s}$ attains a maximum at $2.5 \mathrm{~km}$, which is the top of the trade inversion. The thermal changes are also accompanied by sharp changes in humidity in the vicinity of the stable layers ( $q$ profile). On average, the mixing ratio became almost negligible at an altitude of about $2.5 \mathrm{~km}$. The $\theta_{e}$ and $\theta_{e s}$ profiles are used to estimate the conditionally unstable and trade wind inversion heights because $\theta, \theta_{v}$ and $q$ are not conserved variables. The typical four-layer thermal structure, shown in Fig. 2a, namely mixed layer, transitional layer, conditionally unstable layer and trade wind inversion layer, are characteristically observed up to about (near) the equator during the onward track of the pre-INDOEX.

Further downstream (southward), profiles of $\theta, \theta_{v}, \theta_{e}, \theta_{e s}$ and $q$ at $05^{\circ} 47^{\prime} \mathrm{S} 78^{\circ} 25^{\prime} \mathrm{E}$ during 14:00 IST up to $5 \mathrm{~km}$ altitude are shown in Fig. 2b. Here, a well-mixed layer exists in first $500 \mathrm{~m}$ above the ocean is surface, capped with a weak transition layer. Through the conditionally unstable layer $\theta_{v}$ is increasing according to nearly moist adiabatic ascent while $\theta_{e}$ and $\theta_{e s}$ are approximately constant (indicates moist adiabatic layer) up to $3.3 \mathrm{~km}$. Here several factors can be invoked, like the relatively strong convective activity (mixed layer $\theta_{e} \cong 340 \mathrm{~K}$ and surface $\theta_{e}>345 \mathrm{~K}$ ) at the surface asso- ciated with high moisture content (evident from $q$ profile) in the mixed layer, as well as a weak transition layer, mostly cloudy skies (the difference between $\theta_{e}$ and $\theta_{e s}$ is decreased), all of which could have enabled the increase in the height of the conditionally unstable layer, due to which the trade wind inversion height is forced to greater altitudes of around $3.5 \mathrm{~km}$. Here we observed the clouds, (from manual observations; also $q$ profile shows high moisture content) due to which we renamed the conditionally unstable layer as a cloud layer.

The vertical profiles of $\theta, \theta_{v}, \theta_{e}, \theta_{e s}$ and $q$ at $10^{\circ} 03^{\prime} \mathrm{S}$ $78^{\circ} 57^{\prime} \mathrm{E}$ over the Indian Ocean, near the ITCZ region during 14:00 IST up to $5 \mathrm{~km}$ altitude are shown in Fig. 2c. The mixed layer has a dry adiabatic temperature profile with no measurable inversion at the top. Through the cloud layer $\theta_{v}$ is following a moist adiabatic lapse rate, while $\theta_{e}$ is approximately constant right from the surface up to a higher height. Here, $\theta_{e s}$ profile is approaching the profile of $\theta_{e}$, clearly indicating the existence of saturated layer. The absence of a capping inversion over the mixed layer (surface $\theta_{e}>345 \mathrm{~K}$ ) could have led to the development of clouds with significant vertical extent. Also, the ITCZ is known to be associated with strong surface convergence with thick clouds, whose 
(a)
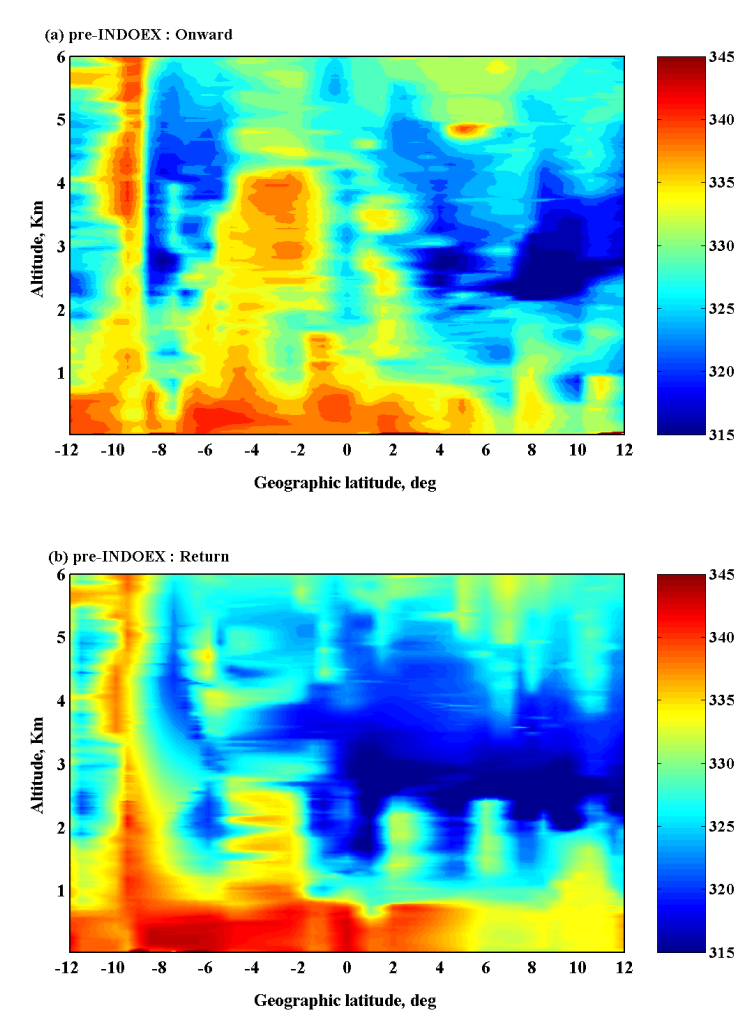

(b)

$$
\mathrm{g} \mathrm{kg}^{-1}
$$
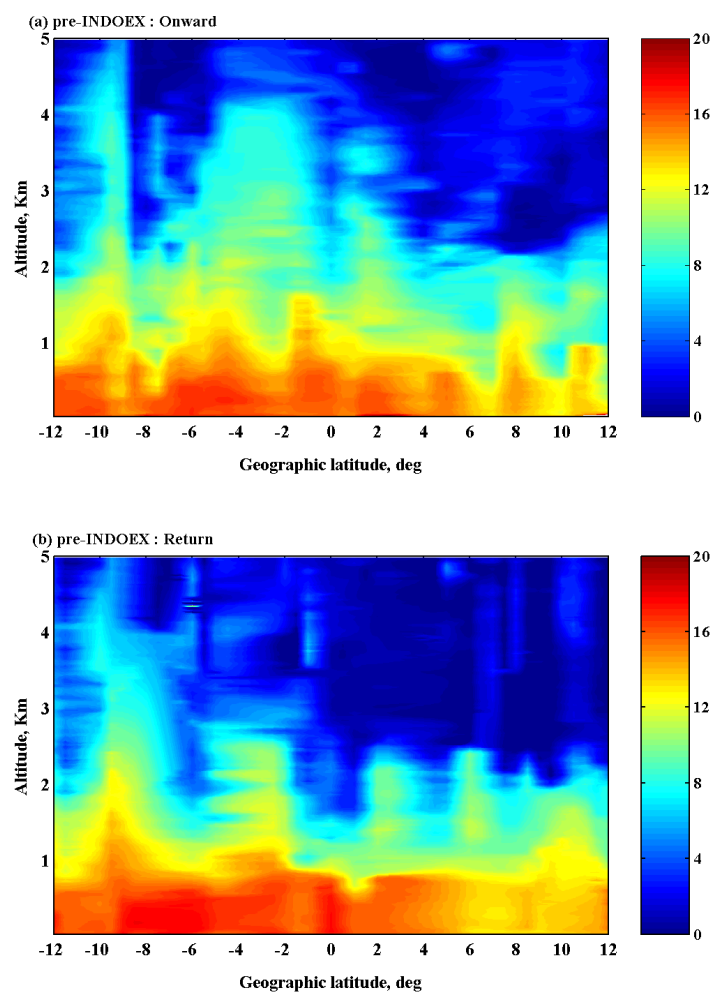

Fig. 5. Contour plots of (a) equivalent potential temperature and (b) mixing ratio over the entire latitude range during pre-INDOEX. The boundary between red and blue is the trade wind inversion layer.
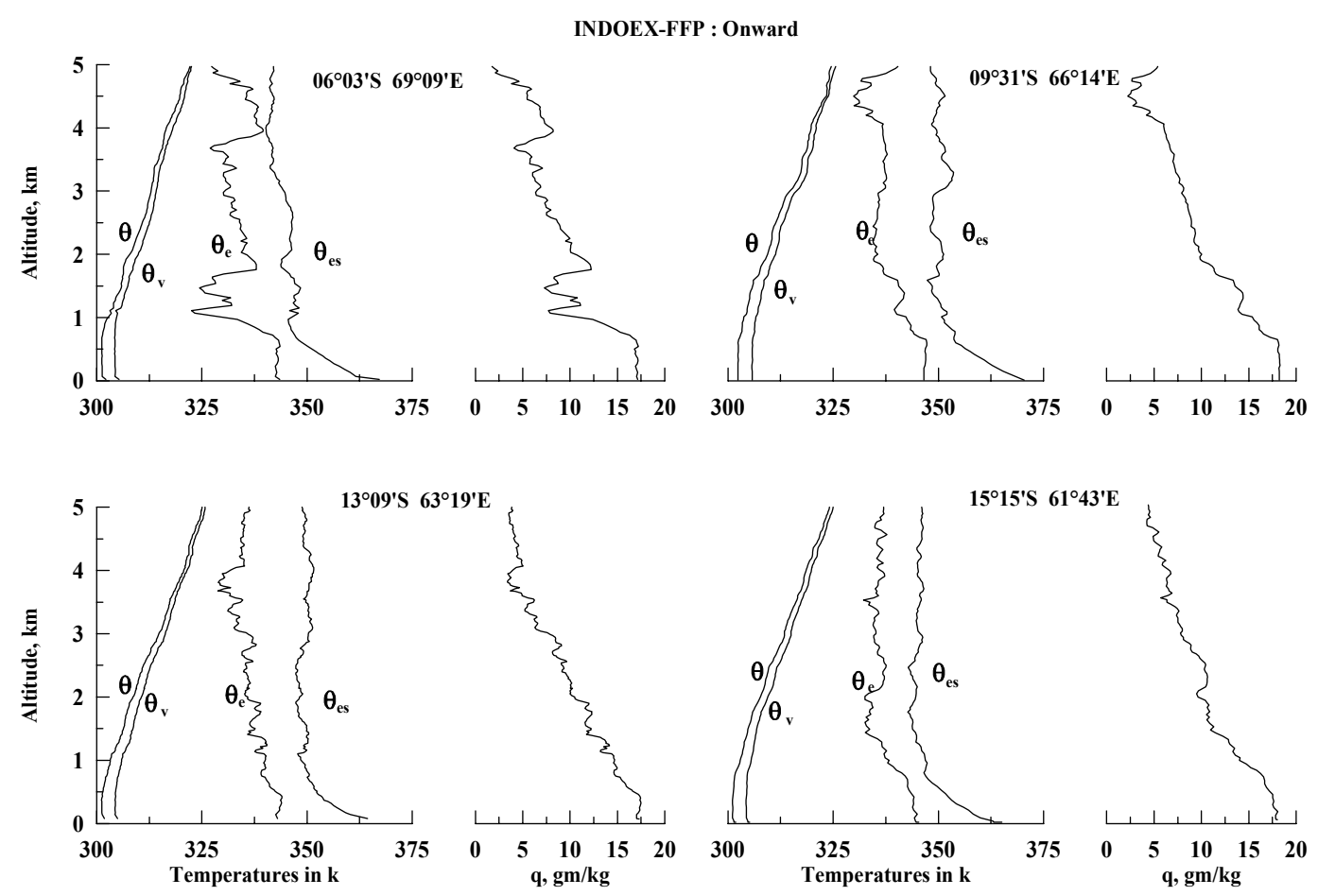

Fig. 6. Altitude profiles of potential temperature $(\theta)$, virtual potential temperature $\left(\theta_{v}\right)$, equivalent potential temperature $\left(\theta_{e}\right)$, saturated equivalent potential temperature $\left(\theta_{e s}\right)$ and mixing ratio $(q)$ during the onward track of INDOEX-FFP. 

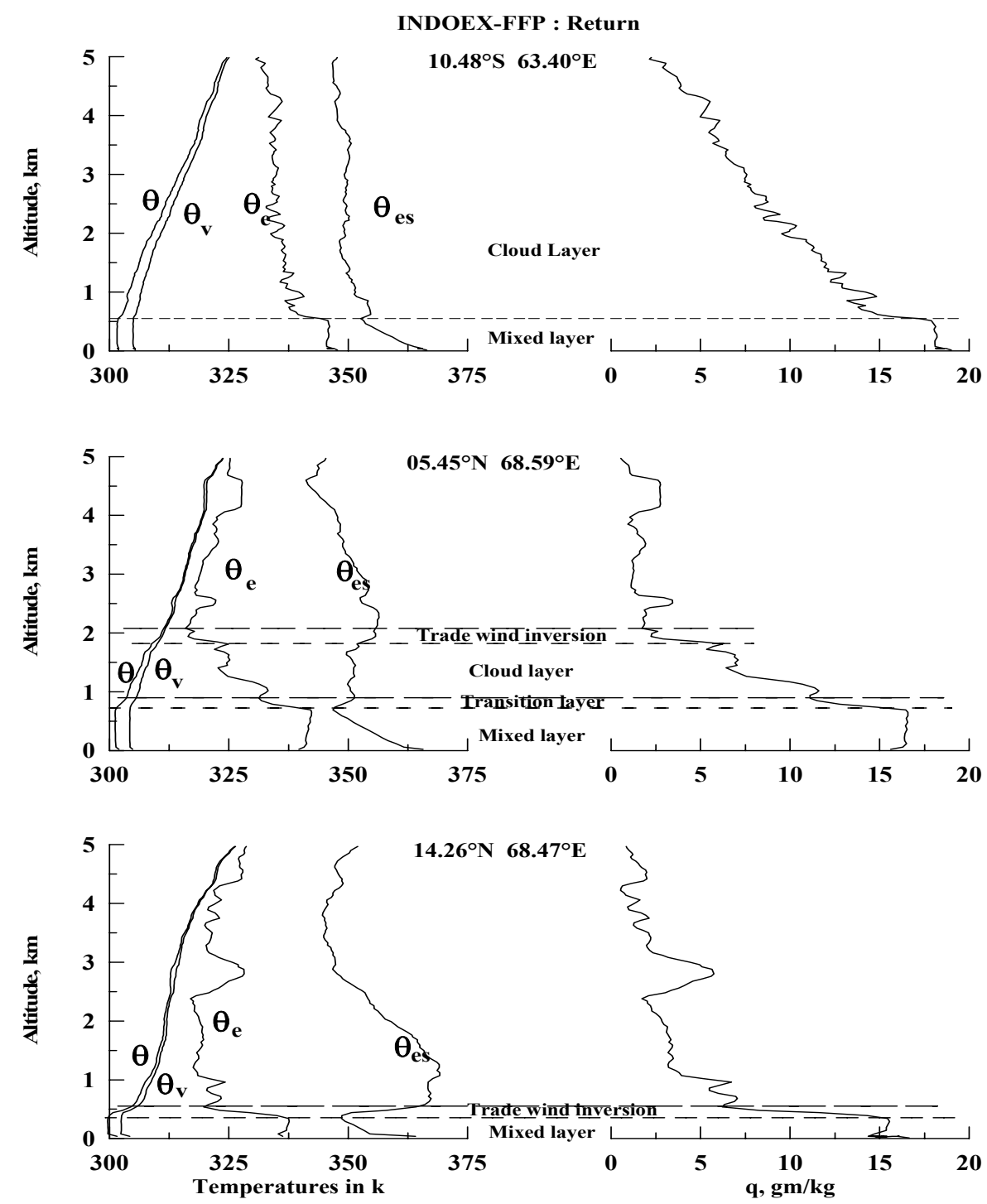

Fig. 7. Altitude profiles of potential temperature $(\theta)$, virtual potential temperature $\left(\theta_{v}\right)$, equivalent potential temperature $\left(\theta_{e}\right)$, saturated equivalent potential temperature $\left(\theta_{e s}\right)$ and mixing ratio $(q)$ during the return track of INDOEX-FFP.

top reaches tropopause. The ITCZ was located at around $7^{\circ} \mathrm{S}$ to $10^{\circ} \mathrm{S}$ during the onward track of the pre-INDOEX (Ramana et al., 2004). Trade wind inversion is not seen in these profiles due to the large extent of cloud layer associated with low-level convergence zone. It is difficult to define the boundary layer top either theoretically or from measurements when deep clouds are present (Stull, 1988; Garratt, 1992).

Figures $3 \mathrm{a}, \mathrm{b}$ and $\mathrm{c}$ show the daytime (14:00 IST) profiles of $\theta, \theta_{v}, \theta_{e}, \theta_{e s}$ and $q$ during the return journey of the pre-INDOEX at $12^{\circ} 07^{\prime} \mathrm{S} 71^{\circ} 42^{\prime} \mathrm{E}, 01^{\circ} 15^{\prime} \mathrm{S} 74^{\circ} 21^{\prime} \mathrm{E}$ and $12^{\circ} 18^{\prime} \mathrm{N} 74^{\circ} \mathrm{E}$, respectively. Return track profiles are following the same pattern as observed in the onward track. In general, surface $\theta_{e}$ values varied from $330 \mathrm{~K}$ at $14^{\circ} \mathrm{N}$ to $349 \mathrm{~K}$ at $12^{\circ} \mathrm{S}$ (near the ITCZ region). It is reported that $\theta_{e}$ values greater than $345 \mathrm{~K}$ are conducive for deep convection in the tropics (Betts and Ridgway, 1989), and $\theta_{e}$ is found to be larger than this critical value near the ITCZ.
Mixed Layer (ML) height, Transition Layer (TL) height, Cloud Layer (CL) height and Trade Wind inversion (TW) heights are derived from all the pre-INDOEX profiles. The maximum uncertainties in these heights are $\sim 30 \mathrm{~m}$, at most. Latitudinal variations of ML, TL, CL and TW heights for onward and return tracks of pre-INDOEX are shown in Figs. 4a, $b$, $c$ and d. Over the ITCZ, the profiles do not show sharp gradients above the mixed layer and therefore an accurate height of the top of trade wind inversion could not be found. On average, the trade wind inversion height is decreased from the disturbed region (near the ITCZ) to the undisturbed region (away from the ITCZ). Low-level clouds are observed in the disturbed (near the ITCZ region) region due to which the mixed layer heights are found to be low in the disturbed area when compared to the undisturbed area. The cloud base is taken as the top of the mixed layer in the disturbed area (Stull, 1988; Garratt, 1992). Using all the CLASS profiles obtained during the cruise, contour plots of $\theta_{e}$ and $q$ over the 

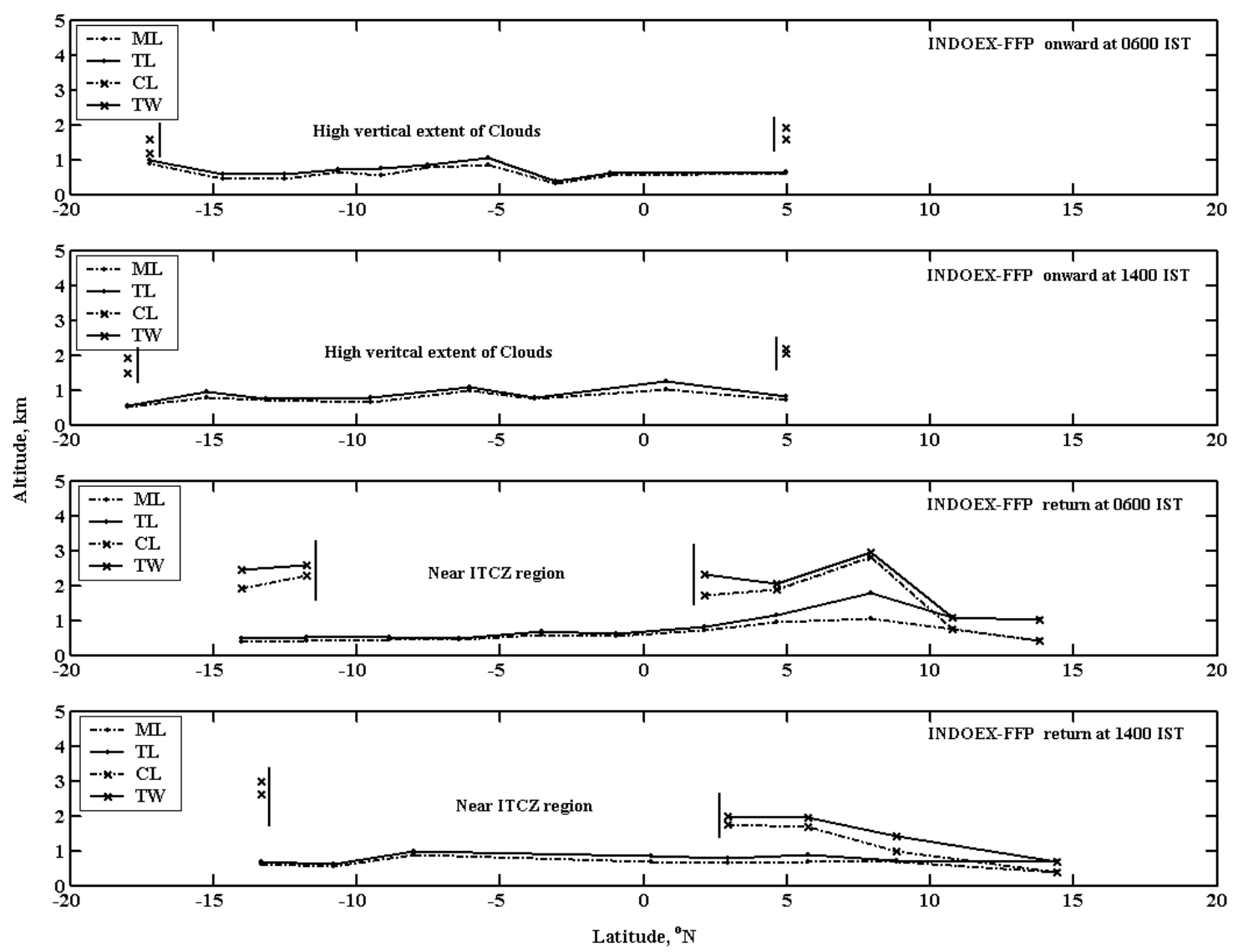

Fig. 8. Latitudinal variation of Mixed Layer (ML) height, Transition Layer (TL) height, Cloud Layer (CL) and Trade Wind inversion (TW) heights during INDOEX-FFP. The continuous and dotted lines joined with the dot symbol represent the TL height and ML height, respectively. The continuous and dotted lines joined with the cross symbol represent TW height and CL height, respectively.

entire latitude range are obtained and are shown in Figs. 5a and $\mathrm{b}$ respectively. The colour scales of $\theta_{e}(\mathrm{~K})$ and $q\left(\mathrm{~g} \cdot \mathrm{kg}^{-1}\right)$ are shown beside the plots. The relatively large $\theta_{e}$ (near surface red colour) close to the surface indicates the strength of the convection activity. The boundary between red and blue (from surface red colour to blue colour) is the trade wind inversion layer top. The thick red area (high values of $\theta_{e}$ ) in Fig. 5a points out the strength of the convection. The trade wind boundary layer height is increasing towards the ITCZ. The ITCZ was located at around $7^{\circ} \mathrm{S}$ to $10^{\circ} \mathrm{S}$ during the onward track of the pre-INDOEX, whereas it was situated south of $10^{\circ} \mathrm{S}$ during the return track (Ramana et al., 2004). The height of the inversion and its thermodynamic properties seem to depend on the balance between the mean atmospheric sinking and the turbulent mixing.

\subsection{INDOEX-FFP}

Figure 6 shows the vertical profiles of $\theta, \theta_{v}, \theta_{e}, \theta_{e s}$ and $q$ measured at 14:00 IST at different latitudes over the Indian Ocean during the onward track of the INDOEX-FFP up to $5 \mathrm{~km}$ altitude in the south of the equator. All these profiles (except $\theta_{e s}$ ) show a shallow layer above the ocean's surface through which the vertical gradients are zero. Above this layer, the profiles indicate the existence of a large vertical extent of clouds. The typical trade wind type of sinking is not observed in these profiles. The surface $\theta_{e}$ also indicates the deep convection, whose values are greater than the critical value for deep convection. We are attributing this deep convection between the equator and $15^{\circ} \mathrm{S}$ to an anomalous event. Webster et al. (1999) reported the existence of an anomalous event during this period over the Indian Ocean (a warm sea surface temperature anomaly developed in the western Indian Ocean; with a maximum of $>+2.0^{\circ} \mathrm{C}$ in February 1998). Ramana et al. (2004) reported high sea surface temperatures and higher sear-air temperature difference $\left(2\right.$ to $\left.3^{\circ} \mathrm{C}\right)$ during the INDOEX-FFP period than the pre-INDOEX sea surface temperatures and sea-air temperature differences $\left(1\right.$ to $\left.2^{\circ} \mathrm{C}\right)$. This region was convectively active during the study period due to higher sea surface temperatures. This deep convection could have affected the marine boundary layer structure in this region.

Figure 7 shows the vertical profiles of $\theta, \theta_{v}, \theta_{e}, \theta_{e s}$ and $q$ measured at 14:00 IST at different latitudes up to $5 \mathrm{~km}$ altitude during the return track of the INDOEX-FFP. The ITCZ is located around $10^{\circ} \mathrm{S}$ during the return track of the INDOEX-FFP (Ramana et al., 2004). Profiles show the 
(a)
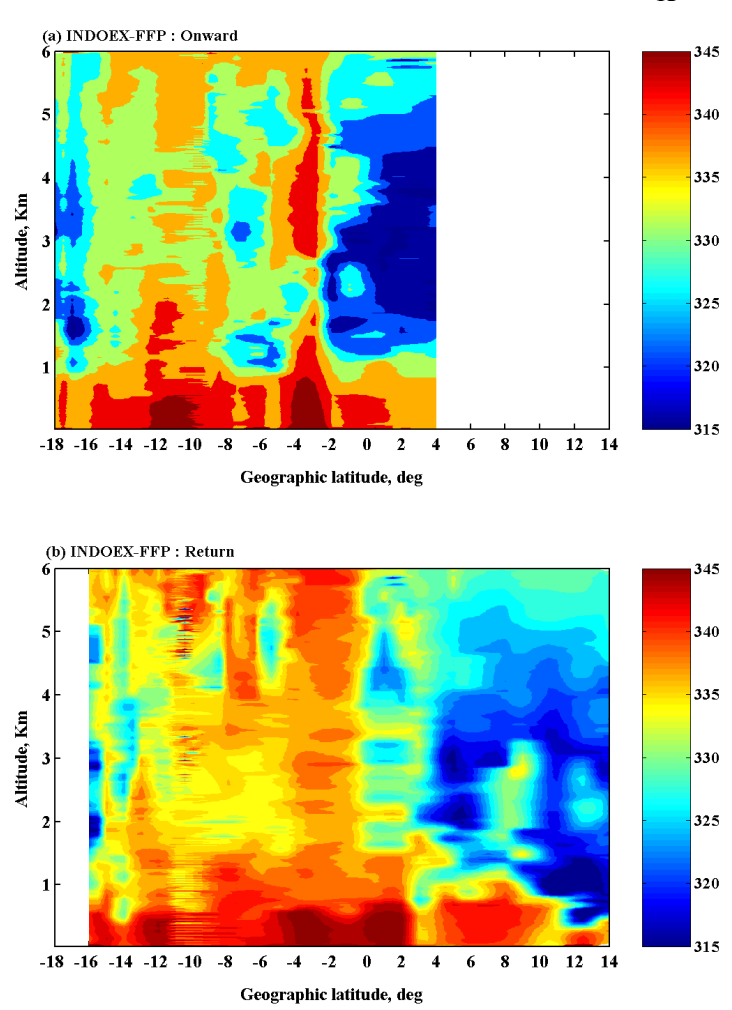

(b)
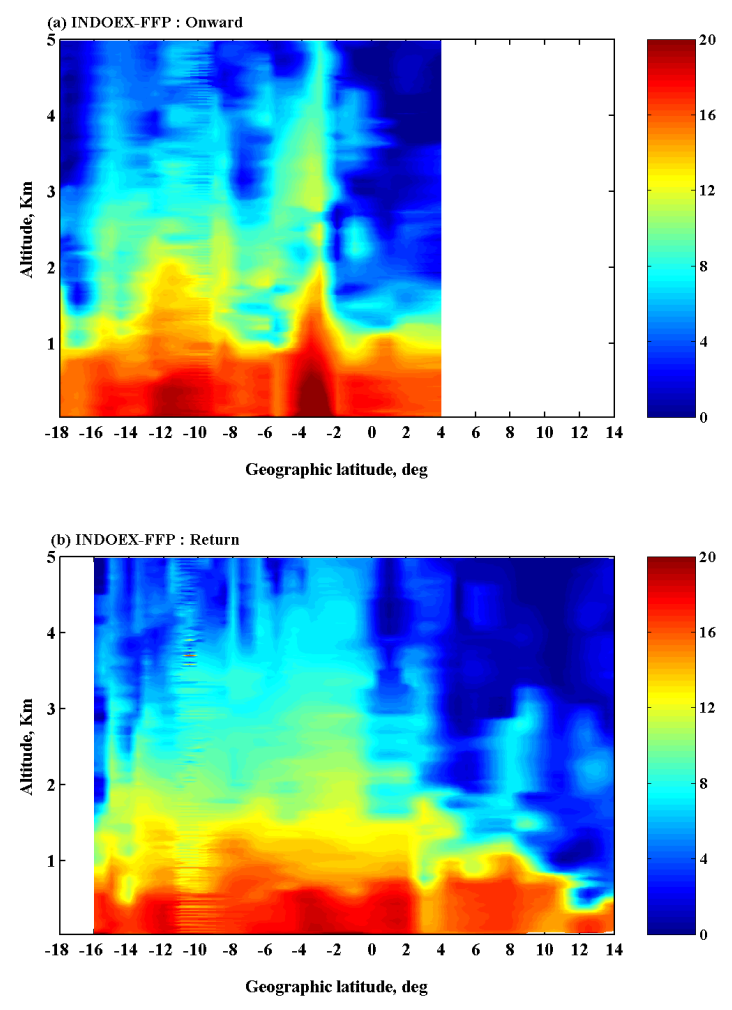

Fig. 9. Contour plots of (a) equivalent potential temperature and (b) mixing ratio over the entire latitude range during INDOEX-FFP. The boundary between red and blue is the trade wind inversion layer.

existence of the trade wind inversion (in Figs. 7b and c) except in the vicinity of the ITCZ (in Fig. 7a). Yu and Rienecker (1999) reported the resumption of a climatological state in March 1998 over the equatorial Indian Ocean region. The trade wind inversion top is located at a lower altitude $(\sim 500 \mathrm{~m})$ in Fig. 7c, indicating the subsidence activity reaching almost right up to the mixed layer top. Except in the regions of large-scale low-level convergence, subsidence prevails in the atmosphere and the subsidence tends to decrease the mixed layer depth by 300 to $400 \mathrm{~m}$ per day (Betts and Ridgway, 1989). The surface fluxes, on the other hand, tend to push the mixed layer upward, and the balance between these two opposing processes decides the actual height of the mixed layer. Therefore, a very strong subsidence must have prevailed to push down the trade wind inversion top to almost close to the surface. Strikingly in this profile a thin layer of warm and high humidity layer at $2.5 \mathrm{~km}$ height is seen. This thin layer is examined using back trajectory analysis, to understand the plausible source regions and is discussed in the following section.

ML, TL, CL and TW heights are derived from all the INDOEX-FFP profiles. Latitudinal variation of ML, TL, CL and TW heights during onward and return tracks of the INDOEX-FFP are shown in Figs. 8a, b, c and d. We find it difficult to locate the trade wind inversion height between the equator and $10^{\circ} \mathrm{S}$ during the onward track, because of the presence of the highly vertical extent of clouds from the surface to $10 \mathrm{~km}$ altitude. In general, mixed layer heights over the Indian Ocean are found to be slightly higher during the INDOEX-FFP compared to the pre-INDOEX; which could be due to the higher sea surface temperatures that prevailed during the INDOEX-FFP (Ramana et al., 2004). The trade wind inversion heights over the Arabian Sea are found to be higher in the pre-INDOEX than the INDOEX-FFP. The CLASS launchings were made only from $4.5^{\circ} \mathrm{N}$ onwards during the onward track of the INDOEX-FFP. Using all the CLASS profiles obtained during the INDOEX-FFP cruise, contour plots of $\theta_{e}$ and $q$ are obtained and shown in Figs. 9a and $\mathrm{b}$ respectively. The colour scale of $\theta_{e}(\mathrm{~K})$ and $q\left(\mathrm{~g} . \mathrm{kg}^{-1}\right)$ are also in the plots. These plots are clearly indicating the trade wind inversion decrease towards $\mathrm{NH}$ (from disturbed area to undisturbed area) and are merging with the mixed layer. Contour plots of equivalent potential temperature are clearly indicating the strong convective activity over the Indian Ocean during the onward as well as during the return tracks. Mixing ratios close to the surface (in the mixed layer) are slightly higher during the INDOEX-FFP than that in the pre- INDOEX cruise period.

To highlight the progressive development of the thin layer at $2.5 \mathrm{~km}$ (which is seen in Fig. 7c) with latitude during the return track of the INDOEX-FFP the $\theta_{e}$ and $R H$ with altitude are shown in Fig. 10. It can be seen from the figure that 

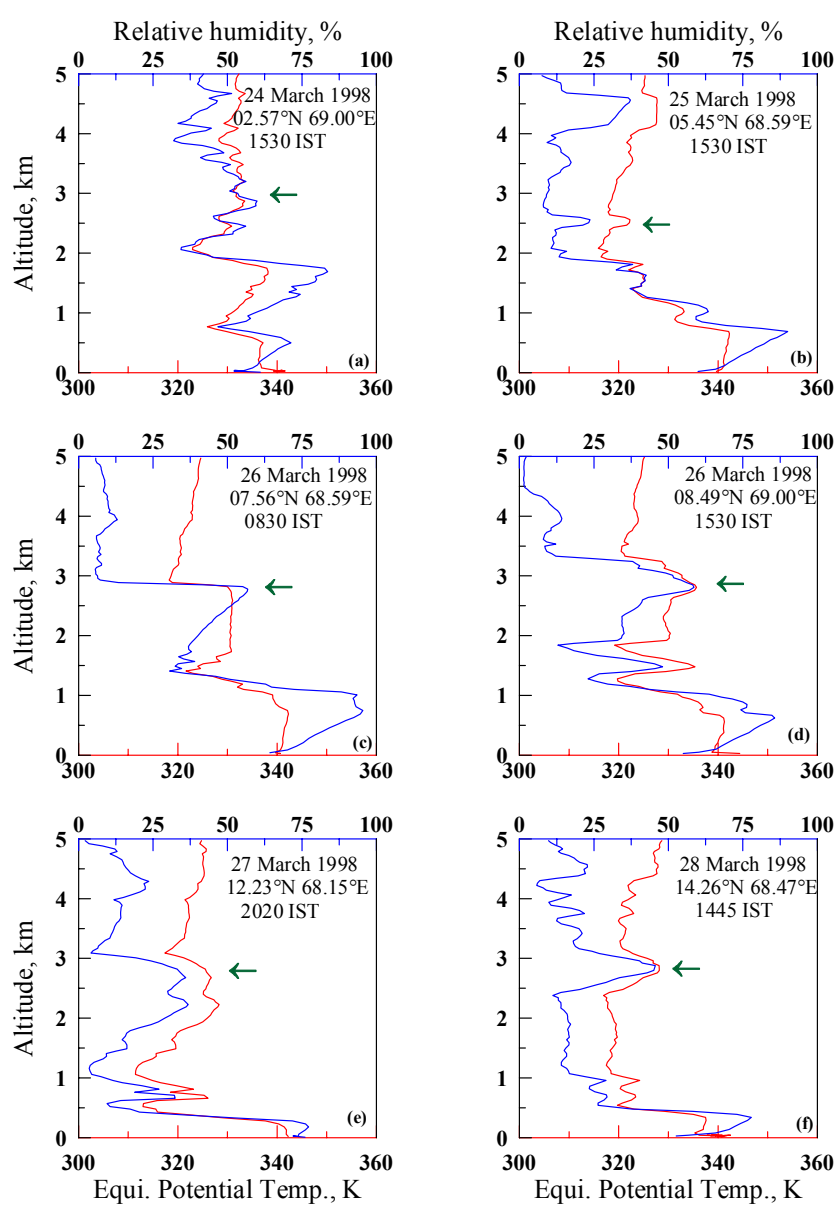

Fig. 10. Altitude profiles of equivalent potential temperature $\left(\theta_{e}\right)$ and relative humidity $(R H)$ showing the progressive development of a layer with $2.5 \mathrm{~km}$ with latitude.

the thin layer developed from $2^{\circ} \mathrm{N}$ to $14^{\circ} \mathrm{N}$. The constant temperature and $R H$ layers in Fig. 10c are characteristics of the existence of land plumes in this region. Krishnamurti et al. (1998) suggested that the thickness of the elevated land plume transported over the ocean might be controlled by the diurnal variability of the atmospheric boundary layer above the land and the height of the trade wind inversion layer. Sea and land breezes are coastal phenomena that further modulate the depth of the continental and marine atmospheric boundary layers (and hence the transport of aerosols). In addition, the heterogeneous surface (the Western Ghats) along the west coast of India could also influence the structure of the land plumes. The depth of the quite variable mixed layer could be due to the complex nature of the land-sea breeze interactions with the offshore flow. Figure 10a shows the multiple layers (at $\sim 3 \mathrm{~km}$ altitude) with different thermal characteristics. South of $2^{\circ} \mathrm{N}$, the land plume takes the form of a faint elevated layer. Light Detection and Ranging (LIDAR) systems have been used during the INDOEX campaigns to derive the aerosol vertical extinction coefficients. Ansmann et al. (2000) reported the existence of an aerosol layer with high humidity (at $2.5 \mathrm{~km}$ altitude) above the marine bound- ary layer at Hulule $\left(4.1^{\circ} \mathrm{N}, 73.3^{\circ} \mathrm{E}\right)$, using six-wavelength aerosol LIDAR. Aerosol vertical extinction coefficients derived by LIDAR profiles showed an increase in the aerosol extinction coefficient inside this observed layer (Ansmann et al., 2000; Muller et al., 2000; 2001a; 2001b).

To identify origins of the aerosols in the land plume, we have performed back trajectory analysis using the NOAA Hybrid Single-Particle Lagrangian Integrated Trajectory (HYSPLIT, Version 4) model (Draxler and Rolph, 2003; Rolph, 2003). Five-day back trajectories at $2.5 \mathrm{~km}$ above the sea level are estimated and are shown in Fig. 11 for those thin layer events that we encountered. The back trajectories describe the history of air parcels back in time, which influenced the aerosol characteristics (hence, thermal characteristics) at the location of measurements. Figure 11 indicates the air mass that travelled all the way to the measurement location. Some of the air parcels came from Saudi Arabia and Iran/Iraq through India, and other from India and Bay of Bengal. Moorthy and Saha (2000) reported high aerosol optical depths during the return track when compared to the onward track (Fig. 3 in their paper). Jayaraman (1999) and Jayaraman et al. (2001) also reported high aerosol optical depths over the Arabian Sea. These plumes could have caused the increase in aerosol optical depths over the Arabian Sea, which suggests long-range transport of continental aerosols over the Arabian Sea.

\section{Discussions and conclusions}

Though a considerable amount of work has gone into studying the structure and characteristics of MABL over the Pacific Ocean and the Atlantic Ocean, the Indian Ocean remained one of the least explored regions. The Indian Ocean Experiment (INDOEX) was the first field experiment of its kind over the Indian Ocean. The INDOEX expedition was carried out in the four successive phases during the 1996 to 1999 Northern Hemisphere winter monsoon seasons, respectively. The present paper describes the results obtained from the pre-INDOEX and the INDOEX-FFP campaigns, which were carried out during winter 1997 and winter 1998, respectively. The study has dealt with descriptive aspects of the spatial and temporal variations of the boundary layer over the Arabian Sea and the Indian Ocean. The primary data used for studying the vertical structure of MABL came from CLASS profiles, collected on board a ship during the pre- INDOEX and the INDOEX-FFP.

The CLASS profiles have shown four layer structures over the Arabian Sea and the Indian Ocean, except in the vicinity of the ITCZ. The mixed layer height ranged from 400 to $900 \mathrm{~m}$ during the pre-INDOEX and 500 to $1100 \mathrm{~m}$ during the INDOEX-FFP, as a function of time and space. The depth of the mixed layer over the Arabian Sea (in the vicinity of land) is observed to be quite variable, and could be due to the complex nature of the land-sea breeze interactions with the offshore flow. The trade wind inversion is located at $\sim 2.5 \mathrm{~km}$ over the Arabian Sea and it varied from 2.5 to $4.5 \mathrm{~km}$ over the 


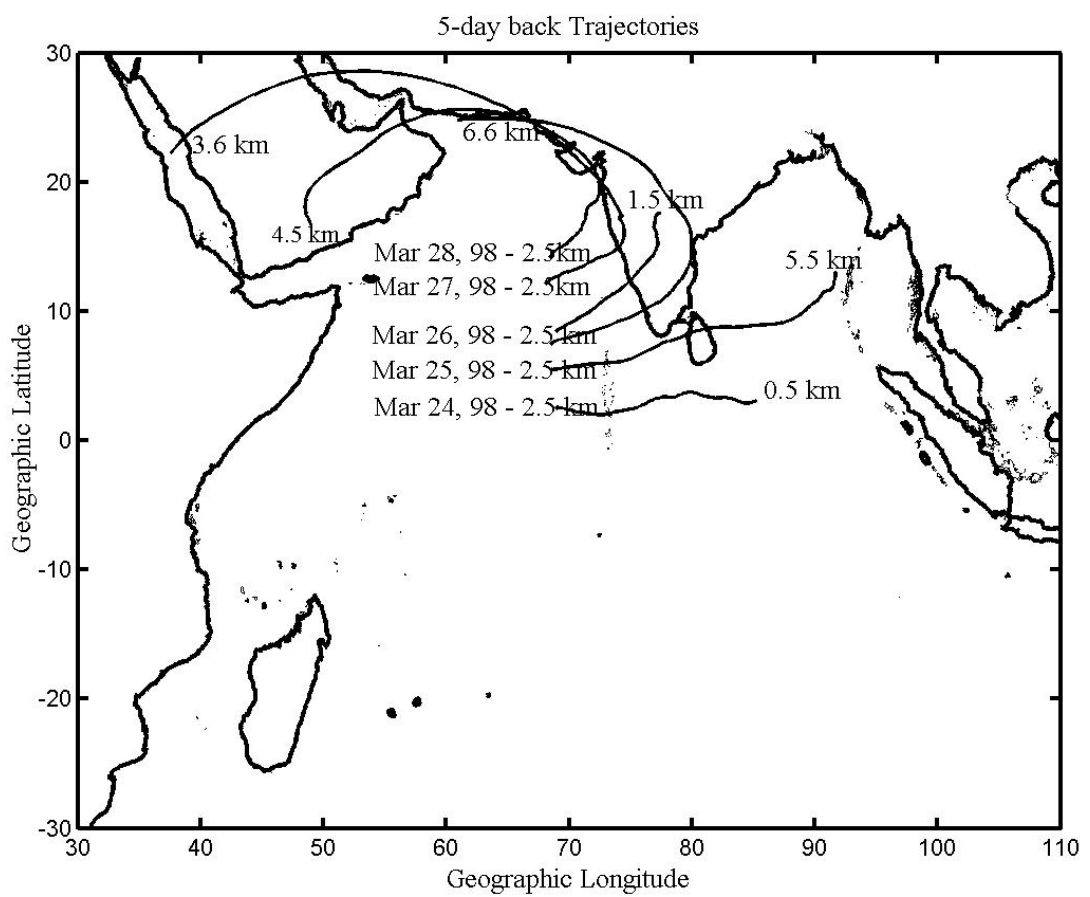

Fig. 11. Five-day back trajectory analysis for the thin layer cases which are shown in Fig. 10. The numbers that are shown at the end of the trajectories indicate the height from where the trajectories are originated.

(Courtesy of NOAA Air Resource Laboratory; http://www.arl.noaa.gov/ready/hysplit4.html)

Indian Ocean during the pre-INDOEX. Trade wind inversion heights over the Arabian Sea are found to be low $(\sim 0.5 \mathrm{~km})$ during the INDOX-FFP due to strong subsidence. The most likely factors responsible for the spatiotemporal variability of the MABL are the proximity of land and the ITCZ. Two prominent features, which characterize the thermodynamic structure of the trade wind boundary layer, are the trade wind inversion and the transition layers, as noticed in the thermodynamic profiles over the undisturbed area (away from the ITCZ). The trade wind inversion and the transition layer show considerable variation in the undisturbed area. The inversion was very strong over the Arabian Sea (with very dry air aloft) and was progressively weaker toward the equator. In the disturbed area (near the ITCZ), the stable layers are weakened. This weakening of stable layers might be caused by the upward energy transport due to active cumulus convection. In this disturbed area, the mixed layer is found to be somewhat lower than that in the undisturbed area due to the existence of low level clouds (near the ITCZ region).

Hastenrath (1991) identified the inversion located at the top of the cloud layer in the undisturbed area over the tropics, typically at an altitude of $2.5 \mathrm{~km}$, as the trade wind inversion and he reported that this inversion is strong and most persistent during the Northern Hemispheric winter. Johnson et al. (1993) have showed the evidence on trade wind inversion heights over the western Pacific warm pool using the TOGA-COARE sounding data, which was found to be horizontally uniform at $800 \mathrm{mb}(\cong 2 \mathrm{~km})$ level. Firestone and Albrecht (1986), Kloesel and Albrecht (1989), and Schubert et al. (1995) have also reported similar trade wind stable lay- ers near $2 \mathrm{~km}$ altitude, extending all the way to the equator in the eastern Pacific and the Atlantic Oceans.

The land plume is formed by air mass modification and its structure is apparent in thermal profiles (presented in this paper) and in aerosol measurement (shown in Ansmann et al., 2000). These land plumes could have a lateral extent of several hundred of kilometres, depending on its trajectory and distance from the coast. According to back trajectory analyses, the air masses composing the elevated plume were coming from Saudi Arabia and Iran/Iraq through India and others from India and the Bay of Bengal. The air mass originated from the land, as the winds were predominantly north-easterly, creating an elevated plume that could potentially transport anthropogenic aerosols and gases over the open ocean, as hypothesized in Lelieveld et al. (2001). The presence of such an aerosol plume over the Arabian Sea and the Indian Ocean could have a significant impact on radiative forcing (Jayaraman et al., 1998), and its analysis can lead to a better understanding of the role of anthropogenic aerosols on Indian monsoon and global climate (Ramanathan and Ramana, 2003).

Acknowledgements. The authors gratefully acknowledge the NOAA Air Resources Laboratory for the provision of the HYSPLIT transport and dispersion model (http://www.arl.noaa.gov/ ready/hysplit4.html) used in this publication. We greatly acknowledge NCAR for launching CLASS balloons during the experiment. We thank anonymous reviewers for their comments on an earlier draft, which helped in improving the paper.

Topical Editor O. Boucher thanks a referee for his help in evaluating this paper. 


\section{References}

Ansmann, A., Althausen, D., Wandinger, U., Franke, K., Muller, D., Wagner, F., and Heintzenberg, J.: Vertical profiling of the Indian aerosol plume with six-wavelength lidar during INDOEX: A first case study, Geophys. Res. Lett., 27, 963-966, 2000.

Augstein, E.: The atmospheric boundary layer over the tropical oceans, Meteorology over the Tropical Oceans, edited by Shaw, D. B., Roy. Meteor. Soc., 73-104, 1978.

Augstein, E., Riehl, H., Ostapoff, F., and Wagner, V.: Mass and energy transport in an undisturbed Atlantic trade wind flow, Mon. Wea. Rev., 101, 101-111, 1973.

Augstein, E., Schmidt, H., and Ostapoff, F.: The vertical structure of the atmospheric planetary boundary layer in undisturbed trade winds over the Atlantic Ocean, Boundary-Layer Meteor., 6, 129150, 1974.

Betts, A. K.: Non-precipitating cumulus convection and its parameterization, Q. J. R. Meteor. Soc., 99, 178-196, 1973.

Betts, A. K. and Ridgway, W.: Climatic equilibrium of the atmospheric convective boundary layer over a tropical ocean, J. Atmos. Sci., 46, 2621-2641, 1989.

Betts, A. K. and Albrecht, B. A.: Conserved variable analysis of the convective boundary layer thermodynamic structure over the tropical oceans, J. Atmos. Sci., 44, 83-99, 1987.

Beyrich, F.: On the estimation of mixed-layer height from Sodar data (A review), in: Proc. 8th ISARS'96 Symposium, Moscow, Russia, 27-31 May 1996, 6.11-6.22, 1996.

Draxler, R. R. and Rolph, G. D.: HYSPLIT (Hybrid Single-Particle Lagrangian Integrated Trajectory) Model access via NOAA ARL READY website (http://www.arl.noaa.gov/ready/hysplit4.html), NOAA Air Resources Laboratory, Silver spring, MD, 2003.

Dunckel, M., Hasse, L., Krugermeyer, L., Schriever, D., and Wucknitz, J.: Turbulent Fluxes of Momentum, Heat, and Moisture in the Atmospheric Surface Layer at Sea during ATEX: Atlantic Trade Winds Experiment, Boundary-Layer Meteorol., 6, 81-106, 1974.

Fairall, C. W., Bradley, E. F., Rogers, D. P., Edson, J. B., and Young, G. S.: Bulk parameterization of air-sea fluxes for Tropical Ocean-Global Atmospheric Coupled Ocean-Atmospheric Response Experiment, J. Geophys. Res., 101, 3747-3764, 1996.

Firestone, J. K. and Albrecht, B. A.: The structure of the Atmospheric Boundary layer in the central equatorial Pacific during January and February of FGGE, Mon. Wea. Rev., 114, 22192231, 1986.

Garratt, J. R.: The Atmospheric Boundary Layer, Cambridge University Press, Cambridge, 316, 1992.

Halpern, D.: Visiting TOGA's past, Bull Amer. Meteorol. Soc., 77(2), 233-242, 1996.

Hastenrath, S.: Climate dynamics of the tropics, Kluwar Acad. Norwell. Mess, 486, 1991.

Holland, J. Z. and Rasmusson, E.: Measurements of the atmospheric mass energy and momentum budget over a 500 kilometer square of tropical ocean, Mon. Wea. Rev., 101, 44-55, 1973.

Houze, R. A. and Betts, A. K.: Convection in GATE, Rev. Geophys. Space Phys., 19, 541-576, 1981.

Jayaraman, A., Lubin, D., Ramachandran, S., Ramanathan, V., Woodbridge, E., Collins, W. D., and Zalpuri, K. S.: Direct observations of aerosol radiative forcing over the tropical Indian Ocean during Jan-Feb 1996 Pre-INDOEX cruise, J. Geophys. Res., 103(D12), 13 827-13 836, 1998.

Jayaraman, A.: Results on direct radiative forcing of aerosols obtained over the tropical Indian Ocean, Curr. Sci., 76, 924-930,
1999.

Jayaraman, A., Satheesh, S. K., Mitra, A. P., and Ramanathan, V.: Latitude gradient in aerosol properties across the Inter Tropical Convergence Zone: Results from the joint Indo-US study on board Sagar Kanya, Curr. Sci., 80, 128-137, 2001.

Johnson, R. H., Bresch, J. F., Ciesielski, P. E., and Gallus, W. A.: The TOGA/COARE atmospheric sounding array: Its performance and preliminary scientific results, 20th Conf. on Hurricanes and Tropical Meteorology, San Antonio, Amer. Meteor. Soc., 1-4, 1993.

Katsaros, K. B., Smith, S. D., and Oost, W. A.: HEXOS-Humidity Exchange over the Sea, A program for research on water vapour and droplet fluxes from sea to air at moderate and high wind speeds, Bull. Amer. Meteor. Soc., 68, 466-476, 1987.

Kloesel, K. A. and Albrecht, B. A.: Low-level inversion over the tropical Pacific - thermodynamic structure of the boundary layer and above inversion moisture structure, Mon. Wea. Rev., 117, 87-101, 1989.

Kondo, J.: Air-Sea Bulk transfer coefficients in Diabatic conditions, Boundary-Layer Meteorol., 9, 91-112, 1975.

Krishnamurti, T. N., Jha, B., Prospero, J., Jayaraman, A., and Ramanathan, V.: Aerosol and pollution transport and their impact on radiative forcing over the tropical Indian Ocean during the January-February 1996 pre-INDOEX cruise, Tellus, Ser. B., 50, 521-542, 1998.

Lelieveld, J., Crutzen, P. J., Ramanathan, V., Andreae, M. O., Brenninkmeijer, A. M., Campos, T., Cass, G. R., Dickerson, R. R., Fischer, H., de Gouw, J. A., Hansel, A., Jefferson, A., Kley, D., de Laat, A. T. J., Lal, A., Lawrence, M. G., Lobert J. M., MayolBracero, O. L., Mitra, A. P., Novakov, T., Oltmans, S. J., Prather, K. A., Reiner, T., Rodhe, H., Scheeren, H. A., Sikka, D., and Williams, J.: The Indian Ocean Experiment: Widespread air pollution from south and southeast Asia, Science, 291, 1031-1036, 2001.

Mitra, A. P.: INDOEX (India): Introductory note, Current Sci., 76, 886-889, 1999.

Mitsuta, Y.: Collected scientific papers of the AMTEX, Japanese National Committee for GARP and Disaster Prevention Research Inst., Kyoto Univ., No.1, No.2; No.3; No.4, 1977-1979.

Moorthy, K. K. and Saha, A: Aerosol study during INDOEX: Observation of enhanced aerosol activity over the Mid Arabian Sea during the northern winter, J. Atmos. Sol. Terr. Phy., 62, 65-72, 2000.

Muller, D., Wagner, F., Althausen, D., Wandinger, and Ansmann, A.: Physical properties of the Indian aerosol plume derived from six-wavelength lidar observations on 25 March 1999 of the Indian Ocean Experiment, Geophys. Res. Lett., 27, 1403-1406, 2000.

Muller, D., Franke, K., Wagner, F., Althausen, D., Ansmann, A., and Heintzenberg, J.: Vertical profiling of optical and physical particle properties over the tropical Indian Ocean with sixwavelength lidar, 1, seasonal cycle, J. Geophys. Res., 106, 28 567-28 575, 2001a.

Muller, D., Franke, K., Wagner, F., Althausen, D., Ansmann, A., Heintzenberg, J., and Verver, G.: Vertical profiling of optical and physical particle properties over the tropical Indian Ocean with six-wavelength lidar, 2, case study, J. Geophys. Res., 106, 28 577-28 595, 2001 b.

Nicholls, S.: Aircraft observations of the Ekman layer during the Joint Air-Sea Interaction Experiment, Quart. J. Roy. Meteor. Soc., 111, 391-426, 1985.

Ramanathan, V., Crutzen, P. J., Coakley, J., Dickerson, R., Heyms- 
field, A., Kiehl, J., Kley, D., Krishnamurti, T. N., Kuettner, J., Lelieveld, J., Mitra, A. P., Prospero, J., Sadourny, R., Valero, F. P. J., and Woodfridge, E. L.: Indian Ocean Experiment (INDOEX) white paper, C4, Scripps Institution of Oceanography, UCSD, La Jolla, California, 1995.

Ramanathan, V. and Ramana, M. V.: Atmospheric Brown Clouds: Long-Range transport and climate impacts, EM, December, 2833, 2003.

Ramana, M. V., Praveena, K., Nair, S. M., and Kunhikrishnan, P. K.: Experimental observations of Air-Sea Parameters and Fluxes associated with anomalous event in the Indian Ocean during 199798 El Niño period, Atmos. Res.,70, 21-32, 2004.

Rolph, G. D.: Real-time Environmental Applications and Display sYstem (READY) website (http://www.arl.noaa.gov/ready/ hysplit4.html), NOAA Air Resources Laboratory, Silver Spring, MD, 2003.

Schubert, W. H., Ciesielski, P. E., Lu, C., and Johnson, R. H.: Dynamical adjustment of the trade wind inversion, J. Atmos. Sci., 52, 2941-2952, 1995.

Shaw, W. A. and Businger, J. A.: Intermittency and the organization of turbulence in the Near-Neutral Marine Atmospheric Boundary Layer, J. Atmos. Sci., 42, 2563-2584, 1985.
Smith, S. D., Anderson, R. J., Oost, W. A., Kraan, C., Maat, N., deCosmo, J., Katsaros, K. B., Davidson, K. L., Bumke, K., Hasse, L., and Chadwick, H. M.: Sea Surface wind stress and Drag Coefficients: The HEXOS results, Boundary-Layer Meteorol., 60, 109-142, 1992.

Stull, R. B.: An introduction to Boundary Layer Meteorology, Kluwer Academic Publishers, The Netherlands, 666, 1988.

Webster, P. J., Moore, A. M., Loschnigg, J. P., and Leben, R. R.: Coupled ocean-atmosphere dynamics in the Indian Ocean during 1997-98, Nature, 401, 356-360, 1999.

Webster, P. J. and Lukas, R.: TOGA-COARE: The Coupled Ocean Atmospheric Response Experiment, Bull. Amer. Meteorol. Soc., 73, 1377-1416, 1992.

Young, G. S., Ledvina, D. R., and Fairall, C. W.: Influence of precipitating convection on the surface energy budget observed during a Tropical Ocean Global Atmospheric pilot cruise in the tropical western Pacific Ocean, J. Geophys. Res., 97, 9595-9603, 1992.

Yu, L. and Rienecker, M. M.: Mechanisms for the Indian Ocean warming during the 1997-98 El Niño, Geophys. Res. Lett., 26, 735-738, 1999. 